\title{
The Influence of Surface Morphology of Buffer Layer on the Critical Current Density in YBCO Coated Conductors
}

\author{
Jie Xiong, Yudong Xia, Fei Zhang, Yan Xue, Kai Hu, \\ Xiaohui Zhao, and Bowan Tao \\ State Key Laboratory of Electronic Thin Film and Integrated Devices, University of Electronic Science and Technology of China, \\ Chengdu 610054, China \\ Correspondence should be addressed to Jie Xiong; jiexiong@uestc.edu.cn and Yudong Xia; xiayudong1983@gmail.com
}

Received 28 October 2013; Accepted 7 November 2013

Academic Editor: Danyang Wang

Copyright ( $\odot 2013$ Jie Xiong et al. This is an open access article distributed under the Creative Commons Attribution License, which permits unrestricted use, distribution, and reproduction in any medium, provided the original work is properly cited.

$1 \mu \mathrm{m}$-thick $\mathrm{YBa}_{2} \mathrm{Cu}_{3} \mathrm{O}_{7-\delta}(\mathrm{YBCO})$ films were grown on the $\mathrm{Y}_{2} \mathrm{O}_{3} /$ yttria stabilized zirconia (YSZ)/CeO $\mathrm{C}_{2}$ buffer layers with different surface morphologies using direct-current sputtering. The critical current density $\left(J_{c}\right)$ value of YBCO was $1.1 \mathrm{MA} / \mathrm{cm}^{2}$ when the root mean square surface roughness $\left(R_{\mathrm{rms}}\right)$ of the buffer layer was $2.5 \mathrm{~nm}$. As the $R_{\mathrm{rms}}$ of the buffer layer increased to $15 \mathrm{~nm}$, the $J_{c}$ decreased to $0.3 \mathrm{MA} / \mathrm{cm}^{2}$. X-ray diffraction and scanning electron microscopy showed the strong relevance of the evolution of the structure and surface morphologies of YBCO films with the buffer layer of different $R_{\mathrm{rms}}$. A model was proposed to explain the influence of surface morphology on the superconducting properties of YBCO films.

\section{Introduction}

Recently, there are more efforts focusing on the fabrication of high performance $\mathrm{YBa}_{2} \mathrm{Cu}_{3} \mathrm{O}_{7-\delta}$ (YBCO) coated conductors on flexible metallic substrates $[1,2]$. The application of 2nd generation coated conductors requires higher current carrying capacity. To reach this goal, a high critical current density $\left(J_{c}\right)$ must be maintained in thick $(>1 \mu \mathrm{m})$ YBCO coatings [3]. Unfortunately, YBCO films deposited on polycrystalline metal substrates showed high angle grain boundaries, leading that the YBCO had a very small critical current [4]. As a result, several methods had been investigated to prepare biaxially aligned templates, such as ion-beam-assisted deposition (IBAD) and rolling assisted biaxially textured substrates (RABiTS) $[5,6]$. The RABiTS approach has been proven to be a simple and cost effective manufacturing technology for mass production of coated conductors.

In order to block the interdiffusion of the metal and oxygen, and minimize the lattice mismatch of YBCO and flexible metallic substrates, one or several layer thin films are deposited on the metallic substrates to serve as the buffer layer for the subsequent YBCO films. Typical tri-layer stack of $\mathrm{CeO}_{2}$ /yttrium stabilized zirconia (YSZ)/ $\mathrm{Y}_{2} \mathrm{O}_{3}$ is one of the mostly explored architectures [7]. In this architecture, the $\mathrm{Y}_{2} \mathrm{O}_{3}$ acts to transfer the biaxial texture from the RABiTS substrate to the YBCO layer; the YSZ layer is used as a barrier to prevent the interdiffusion between oxides and metal substrate; the $\mathrm{CeO}_{2}$ cap layer on YSZ layer provides good lattice matching and an epitaxial growth template for depositing the YBCO layer. Therefore, buffer layers play a critical role in fabricating high performance coated conductors. So far, enormous efforts had been made toward the manufacture of the biaxial texture of buffer layers on the RABiTS tapes; however, the cap layer had not been paid enough attention [8-10]. In our previous work, we had reported the surface morphology evolvement of the $\mathrm{CeO}_{2}$ films deposited on the $\mathrm{YSZ} / \mathrm{Y}_{2} \mathrm{O}_{3} / \mathrm{Ni}$-alloy substrates $[11,12]$. In this study, we investigated in detail the impact of the surface morphologies of buffer layers on the superconducting properties in $\mathrm{YBCO}$ films.

\section{Experimental Details}

Biaxially textured $\{100\}\langle 100\rangle \mathrm{Ni}-5$ at.\%W alloy (NiW) tapes were used in this study, which were supplied from EVICO $\mathrm{GmbH}$, Germany. The full width at half maximum (FWHM) 


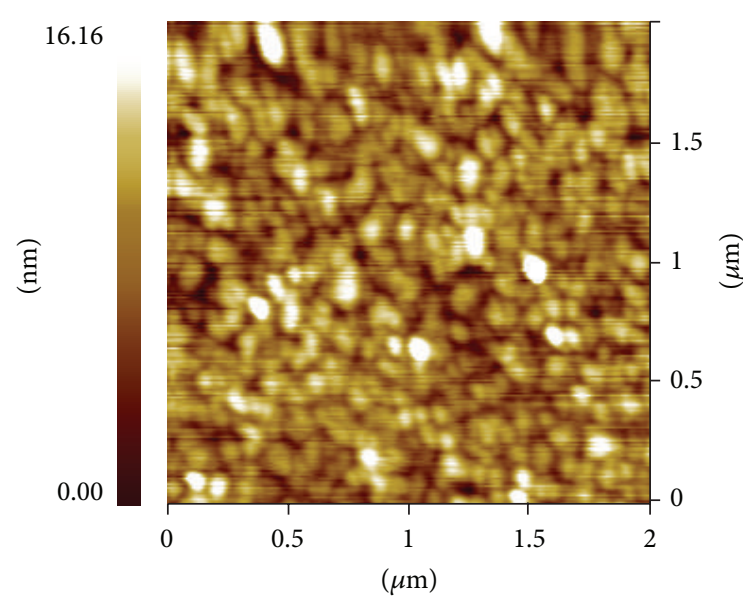

(a)

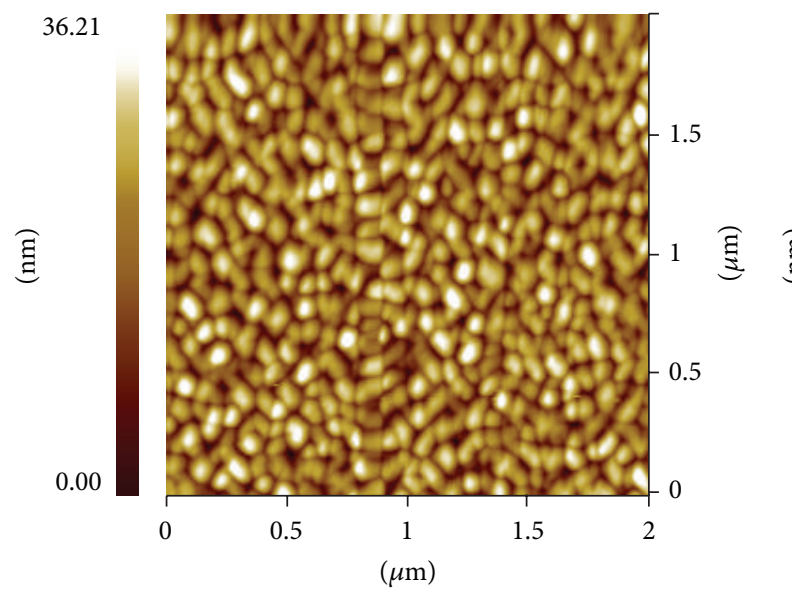

(c)

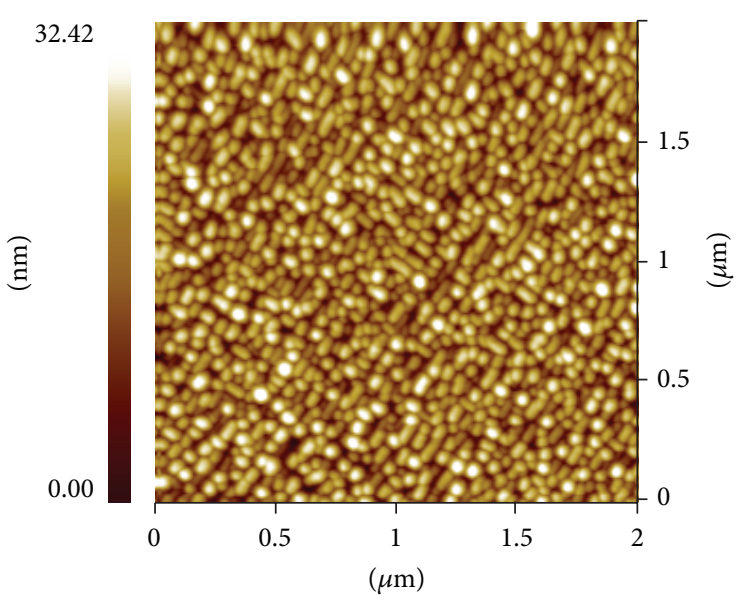

(b)

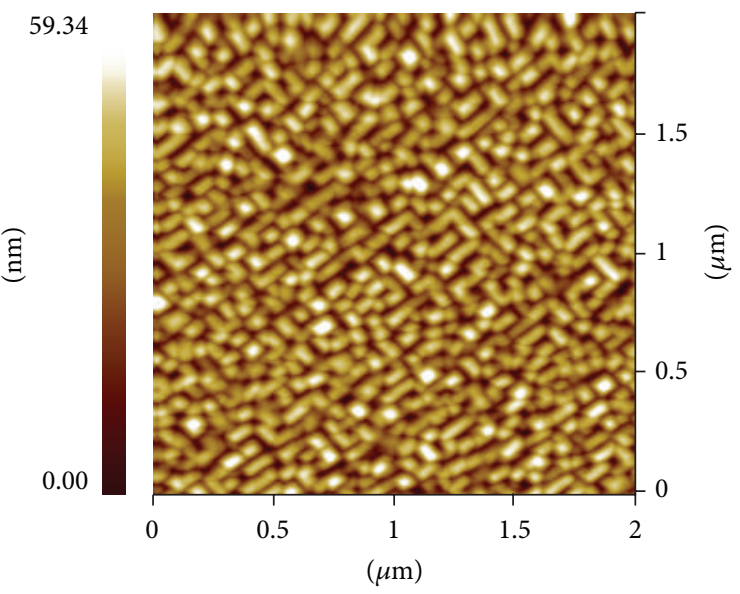

(d)

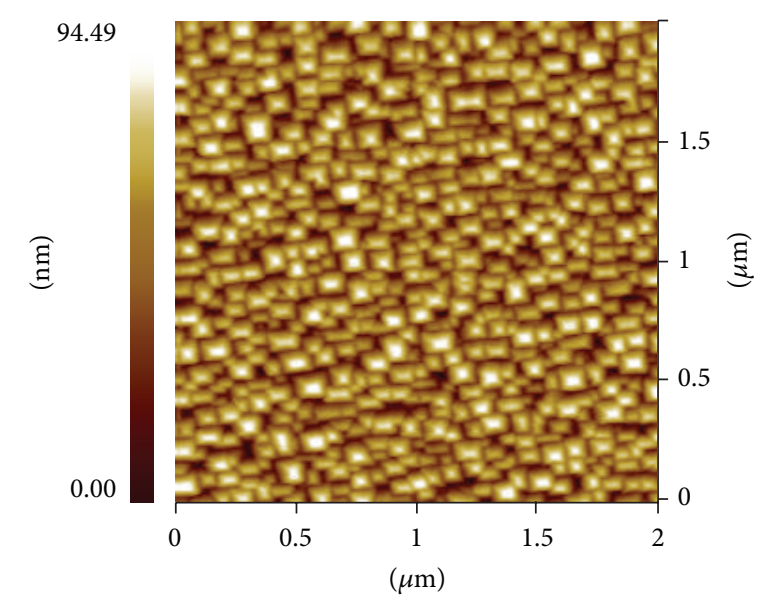

(e)

Figure 1: AFM images of different $\mathrm{CeO}_{2}$ cap layers.

values of out-of-plane and in-plane were about $5.5^{\circ}$ and $6^{\circ}$, respectively. The $\mathrm{Y}_{2} \mathrm{O}_{3} / \mathrm{YSZ} / \mathrm{CeO}_{2}$ multilayers with different surface morphologies were deposited on NiW tapes using reel-to-reel direct-current (DC) reactive magnetron sputtering by modulating the substrate temperature from $500^{\circ} \mathrm{C}$ to $680^{\circ} \mathrm{C}$ as reported in [12]. The thickness of all $\mathrm{CeO}_{2}$ cap layers was $40 \mathrm{~nm}$. The subsequent YBCO films were prepared by DC sputtering with the same conditions, which were initially optimized. Detailed conditions were reported elsewhere [3]. 


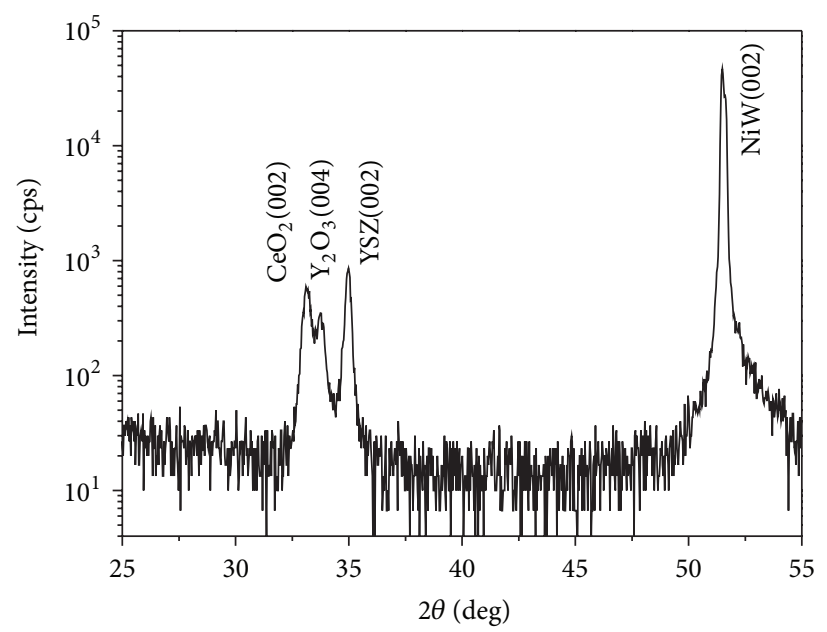

(a)

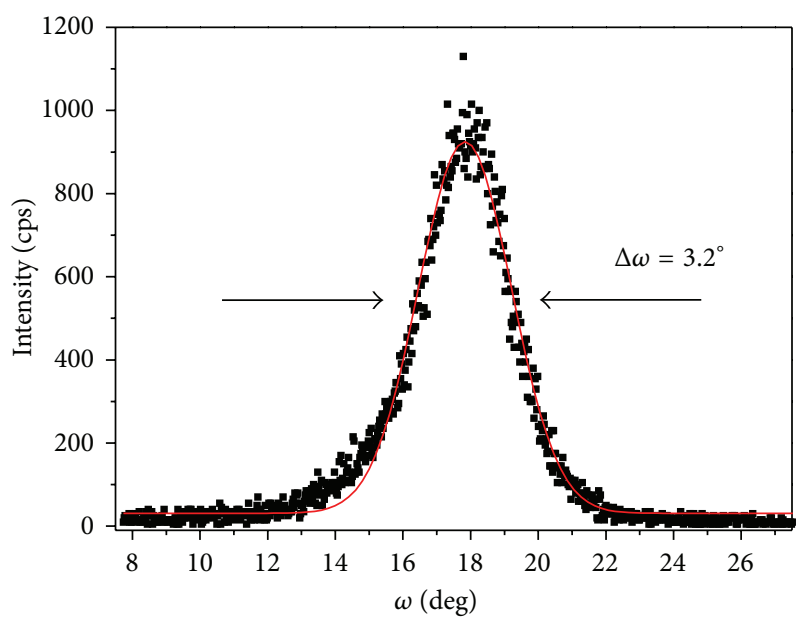

- $\mathrm{CeO}_{2}(002): \omega$-scan

Gauss fit of $\omega$-scan

(b)

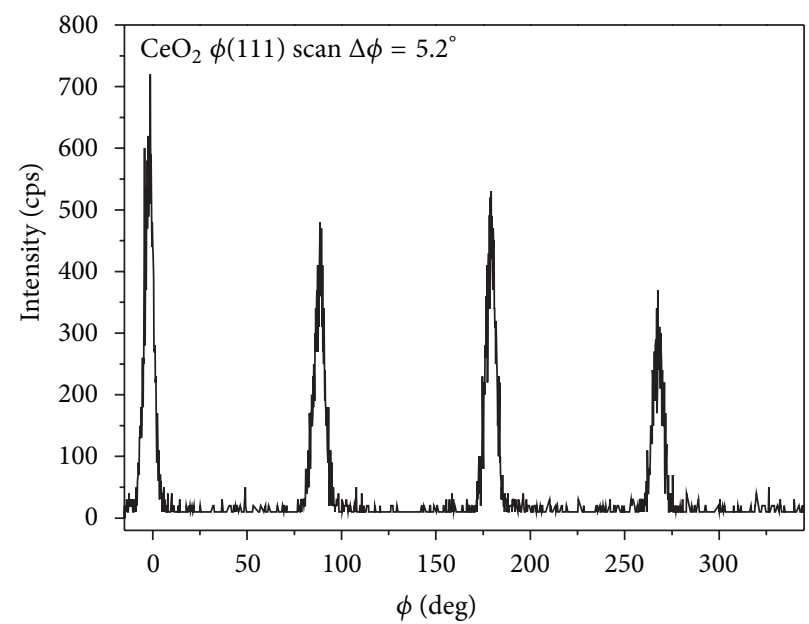

(c)

FIgure 2: Typical XRD patterns of $\mathrm{CeO}_{2} / \mathrm{YSZ} \mathrm{Y}_{2} \mathrm{O}_{3}$ buffer layer (a) $\theta-2 \theta$ scan, (b) $\omega$-scan of (002) $\mathrm{CeO}_{2}$, and (c) $\phi$-scan of (111) CeO .

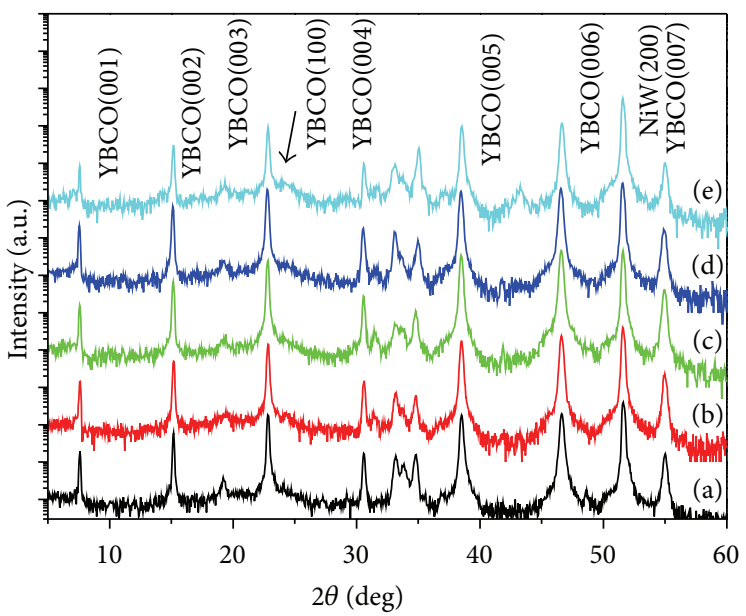

FIGURE 3: XRD $\theta-2 \theta$ patterns of YBCO films deposited on the buffers of samples from (a) to (e). 


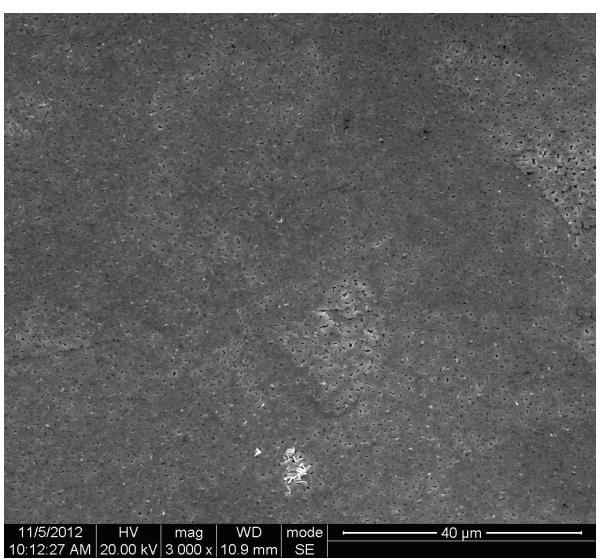

(a)

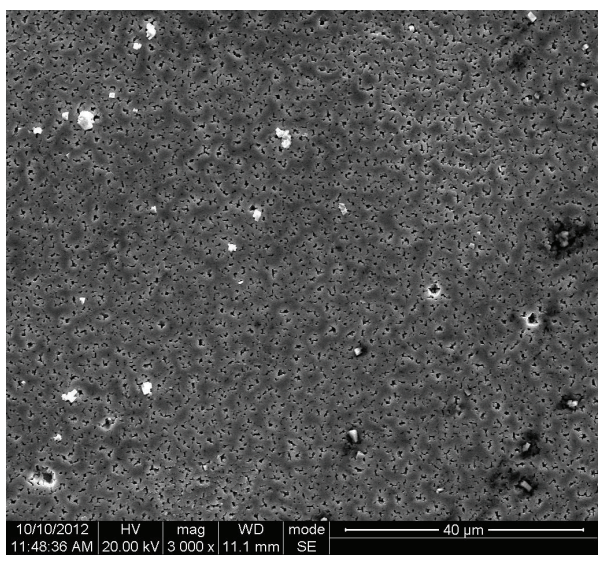

(c)

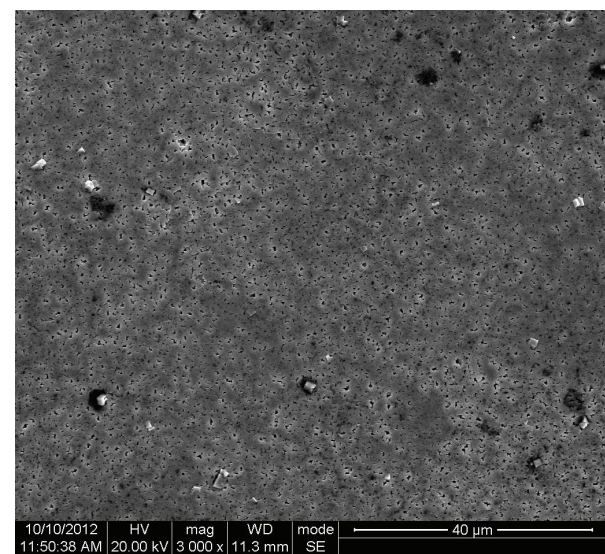

(b)

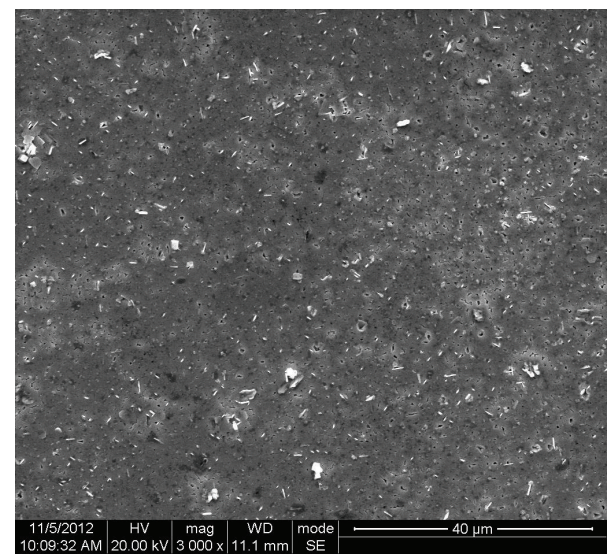

(d)

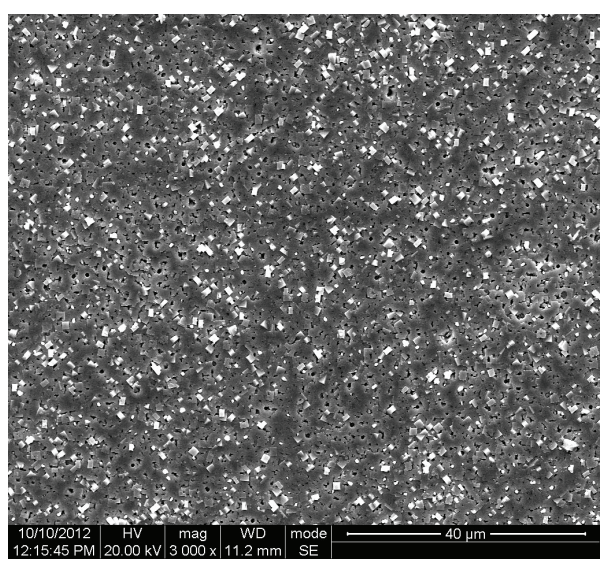

(e)

FIGURE 4: SEM images of YBCO films deposited on different surface morphologies of buffer layers.

The film structure was measured with Bede X-ray diffraction (XRD) system including $\theta-2 \theta, \omega$, and $\phi$-scan. Atomic force microscopy (AFM, SEIKO SPA300HA microscopy) and scanning electron microscopy (SEM, JSM-5900) were used to characterize the surface morphology and calculate the root mean square surface roughness $\left(R_{\mathrm{rms}}\right) . J_{c}$-Scan system developed by Germany Leipzig University was used to measure the $J_{c}$ values.

\section{Results and Discussion}

Figure 1 shows the surface morphologies of the different $\mathrm{CeO}_{2}$ layers for this series experiments. The $R_{\mathrm{rms}}$ values of the 
TABLE 1: The $R_{\text {rms }}$ of the buffer layers and the values of out-of-plane and in-plane textures of the corresponding YBCO films.

\begin{tabular}{lccccc}
\hline Sample & $\mathrm{a}$ & $\mathrm{b}$ & $\mathrm{c}$ & $\mathrm{d}$ & $\mathrm{e}$ \\
\hline$R_{\mathrm{rms}}$ of $\mathrm{CeO}_{2}$ & $2.5 \mathrm{~nm}$ & $4.6 \mathrm{~nm}$ & $5.8 \mathrm{~nm}$ & $9.5 \mathrm{~nm}$ & $15.2 \mathrm{~nm}$ \\
$\Delta \omega$ of $(002) \mathrm{YBCO}$ & $2.37^{\circ}$ & $2.98^{\circ}$ & $2.92^{\circ}$ & $2.97^{\circ}$ & $3.2^{\circ}$ \\
$\Delta \phi$ of $(103) \mathrm{YBCO}$ & $4.91^{\circ}$ & $4.77^{\circ}$ & $5.07^{\circ}$ & $4.72^{\circ}$ & $5.48^{\circ}$ \\
\hline
\end{tabular}

$\mathrm{CeO}_{2}$ films from (a) to (e) are shown in Table 1. The XRD $\theta-2 \theta$ scan, $\omega$-scan of $\mathrm{CeO}_{2}$ (200) peak, and $\phi$-scan of $\mathrm{CeO}_{2}$ (111) plane are shown in Figures 2(a), 2(b), and 2(c), respectively; all the $\mathrm{Y}_{2} \mathrm{O}_{3} / \mathrm{YSZ} / \mathrm{CeO}_{2}$ films are completely $c$-axis oriented with representative in-plane FWHM value of $5.2^{\circ}$ and out-ofplane FWHM value of $3.2^{\circ}$.

The XRD patterns of YBCO films deposited on the buffer samples from (a) to (e) are shown in Figure 3. The deposition time was 20 hours and the typical thickness of YBCO film was $1 \mu \mathrm{m}$. The $2 \theta$ peaks at $33.02^{\circ}, 33.8^{\circ}$, and $34.9^{\circ}$ were indexed as the $(00 l)$ reflections of $\mathrm{CeO}_{2}, \mathrm{Y}_{2} \mathrm{O}_{3}$, and YSZ, respectively. Weak $\mathrm{NiO}$ and $\mathrm{NiWO}_{4}$ reflections were observed at the $2 \theta$ angles of $19.28^{\circ}, 37.26^{\circ}$, and $43.29^{\circ}$. All of the patterns indicated pure $c$-axis orientation except for the sample (e), which had a small amount of $a$-axis grains. The out-ofplane and in-plane textures of YBCO films deposited on samples from (a) to (e) are documented in Table 1. With the exception of the YBCO deposited on sample (e), all the out-of-plane FWHM values of YBCO films were smaller than $3^{\circ}$, demonstrating good out-of-plane alignments. The FWHM values of sample (e) were slightly bigger than others, ascribed to the $a$-axis grains, and leaded to the formation of high angle grain boundaries in the YBCO film. The inplane FWHM values of YBCO films were between $4.7^{\circ}$ and $5.5^{\circ}$, indicating no obvious tendency on the in-plane texture when the YBCO films deposited on different buffer layers.

The SEM images of YBCO films deposited on different surface morphologies of $\mathrm{CeO}_{2}$ cap layers are shown in Figure 4, which corresponded with (a) to (e) of Figure 1, respectively. Figure 4(a) showed the relative flattest surface morphology with typical small holes attributed to the rich yttrium in YBCO films [13]. As the $R_{\mathrm{rms}}$ of the buffer layers increased, the holes on the surface of the YBCO films became bigger, as observed in Figures 4(b) and 4(c). As the $R_{\mathrm{rms}}$ of the buffer layers increased more than $10 \mathrm{~nm}$, the needle-like $a$-axis particles of YBCO films were distributed on the surface of YBCO film shown in Figures 4(d) and 4(e).

The relationship between the $J_{c}$ of corresponding YBCO films is sketched in Figure 5. The $J_{c}$ of YBCO deposited on the buffer of sample (a) was $1.1 \mathrm{MA} / \mathrm{cm}^{2}$. The YBCO deposited on samples (b)-(d) showed $J_{c}$ values of $0.9 \mathrm{MA} / \mathrm{cm}^{2}$, $0.8 \mathrm{MA} / \mathrm{cm}^{2}$, and $0.5 \mathrm{MA} / \mathrm{cm}^{2}$, respectively. As the $R_{\mathrm{rms}}$ of the buffer layers increased to $15 \mathrm{~nm}$, the $J_{c}$ value of YBCO films continuously decreased to $0.3 \mathrm{MA} / \mathrm{cm}^{2}$, revealing the strong relevance between the superconducting properties and the surface morphology.

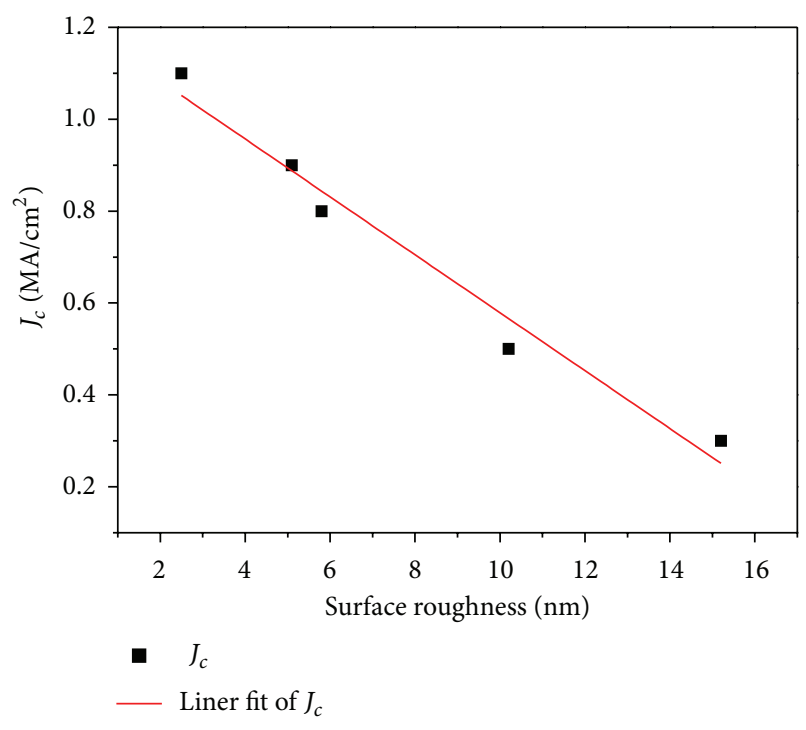

FIGURE 5: The relationship between the $J_{c}$ of YBCO films and surface morphologies of $\mathrm{CeO}_{2}$ layers.

In order to study the mechanism of the effect of the buffers' surface on the performance of YBCO films, the corresponding line profiles of $\mathrm{CeO}_{2}$ films of samples (a) and (e) were plotted in Figures 6(a) and 6(b), respectively. As shown in Figure 6, the grain height was in the range of $-50 \mathrm{~nm} \sim 50 \mathrm{~nm}$, and the gap between in grain boundaries of sample (a) was much smaller than that of sample (e). In the sputter process, the sputter atoms diffused and nucleated on the substrate surface. However, YBCO is a multielement oxide with different atom radii of $\mathrm{Y}, \mathrm{Ba}$, and $\mathrm{Cu}$. For different surface morphologies of $\mathrm{CeO}_{2}$ films such as sample (e), the gap between grain boundaries was deeper and the grain boundaries area was larger than that of sample (a). If metal atoms diffused from one grain of $\mathrm{CeO}_{2}$ surface to another, it should overcome the superior potential barrier, while the potential barrier of a $\mathrm{Ba}$ atom is bigger than that of $\mathrm{Cu}$ and $\mathrm{Y}$ atoms. Therefore, if the grain boundary area was large, $\mathrm{Ba}$ atoms would be enriched on the grain boundaries, which led to the deviation of YBCO chemical contents, and as observed white particles formed on the surface in Figure 4(e), which was identified as the $\mathrm{CuO}$ nonconductive particles. Further demonstrations are necessary for a better understanding by transmission electron microscopy which is ongoing.

\section{Conclusions}

The influence of surface morphologies of $\mathrm{CeO}_{2}$ cap layers on the microstructure and critical current density of YBCO films was systematically investigated. YBCO films on the flat surface revealed high quality epitaxial $c$-axis oriented growth and had much better superconducting properties. As the $R_{\mathrm{rms}}$ of the buffer layer increased, the nonconductive particles and $a$-axis grains on the surface of YBCO were observed, leading to deteriorating the $J_{c}$ of YBCO films. A model was proposed to understand the phenomena, demonstrating 


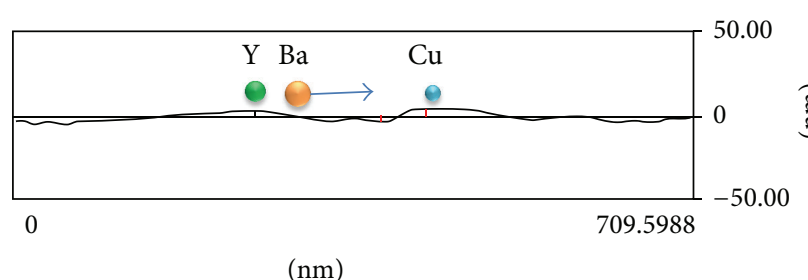

(a)

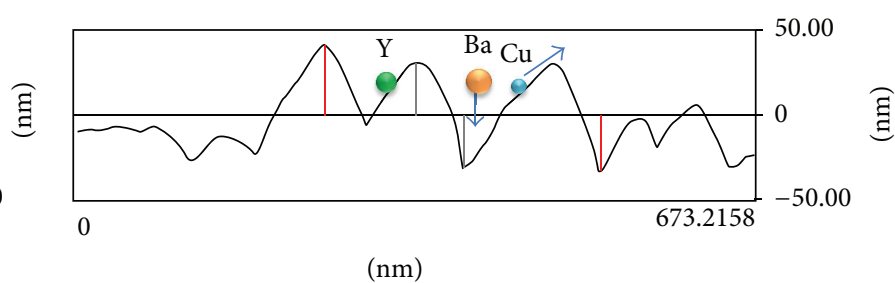

(b)

Figure 6: The corresponding line profiles of $\mathrm{CeO}_{2}$ films (a) of sample (a) and (b) of sample (e).

that the surface morphology of buffer layers had a strong effect on the current carrying capacity of YBCO coated conductors.

\section{Acknowledgments}

The authors gratefully acknowledge the support of the National Natural Science Foundation of China under Grant no. 51002024, Sichuan Youth Science and Technology Innovation Research Team Funding (no. 2011JTD0006), and Fundamental Research Funds for the Central Universities (no. ZYGX2012J039 and ZYGX2011Z002) for this work.

\section{References}

[1] D. P. Norton, A. Goyal, J. D. Budai et al., "Epitaxial $\mathrm{YBa}_{2} \mathrm{Cu}_{3} \mathrm{O}_{7}$ on biaxially textured nickel (001): an approach to superconducting tapes with high critical current density," Science, vol. 274, no. 5288, pp. 755-757, 1996.

[2] D. P. Norton, A. Goyal, J. D. Budai et al., "High critical current density superconducting tapes by epitaxial deposition of $\mathrm{YBa}_{2} \mathrm{Cu}_{3} \mathrm{O}_{x}$ thick films on biaxially textured metals," Applied Physics Letters, vol. 69, no. 12, article 1795, 1996.

[3] J. Xiong, B. W. Tao, W. F. Qin et al., "Reel-to-reel continuous simultaneous double-sided deposition of highly textured $\mathrm{CeO}_{2}$ templates for $\mathrm{YBa}_{2} \mathrm{Cu}_{3} \mathrm{O}_{7-\delta}$ coated conductors," Superconductor Science and Technology, vol. 21, no. 2, Article ID 025016, 2008.

[4] D. Dimos, P. Chaudhari, and J. Mannhart, "Superconducting transport properties of grain boundaries in $\mathrm{YBa}_{2} \mathrm{Cu}_{3} \mathrm{O}_{7}$ bicrystals," Physical Review B, vol. 41, no. 7, pp. 4038-4049, 1990.

[5] Y. Iijima, N. Tanabe, O. Kohno et al., "In-plane aligned $\mathrm{YBa}_{2}$ $\mathrm{Cu}_{3} \mathrm{O}_{7-x}$ thin films deposited on polycrystalline metallic substrates," Applied Physics Letters, vol. 60, no. 6, artcile 769, 1992.

[6] E. D. Specht, A. Goyal, D. F. Lee et al., "Cube-textured nickel substrates for high-temperature superconductors," Superconductor Science and Technology, vol. 11, no. 10, article 945, 1998.

[7] X. Li, M. W. Rupich, T. Kodenkandath et al., "High critical current YBCO films prepared by an MOD process on RABiTS templates," IEEE Transactions on Applied Superconductivity, vol. 17, no. 2, pp. 3553-3556, 2007.

[8] T. Aytug, M. Paranthaman, H. Y. Zhai et al., "Single buffer layers of $\mathrm{LaMnO}_{3}$ or $\mathrm{La}_{0.7} \mathrm{Sr}_{0.3} \mathrm{MnO}_{3}$ for the development of $\mathrm{YBa}_{2} \mathrm{Cu}_{3} \mathrm{O}_{7-\delta}$-coated conductors: a comparative study," Journal of Materials Research, vol. 17, no. 9, pp. 2193-2396, 2002.

[9] J. Xiong, Y. Chen, Y. Qiu et al., "A novel process for $\mathrm{CeO}_{2}$ single buffer layer on biaxially textured metal substrates in YBCO coated conductors," Superconductor Science and Technology, vol. 19, no. 10, article 1068, 2006.
[10] D. Q. Shi, R. K. Ko, K. J. Song et al., "Deposition of $\mathrm{Y}_{2} \mathrm{O}_{3}$ film on textured metal substrates for a single buffer layer of a YBCO coated conductor," Superconductor Science and Technology, vol. 18, no. 4, article 561, 2005.

[11] Y. D. Xia, J. Xiong, F. Zhang et al., "Reel-to-reel deposition of epitaxial double-sided $\mathrm{Y}_{2} \mathrm{O}_{3}$ buffer layers for coated conductors," Physica C, vol. 476, pp. 48-53, 2012.

[12] Y. D. Xia, J. Xiong, and F. Zhang, "Morphology evolvement of $\mathrm{CeO}_{2}$ cap layer for coated conductors," Applied Surface Science, vol. 263, pp. 508-512, 2012.

[13] J. Xiong, W. F. Qin, J. L. Tang, B. Tao, X. Cui, and Y. Li, "Preparation and characterization of microcrack-free thick $\mathrm{YBa}_{2}$ $\mathrm{Cu}_{3} \mathrm{O}_{7-\delta}$ films," Rare Metals, vol. 26, no. 5, pp. 403-407, 2007. 

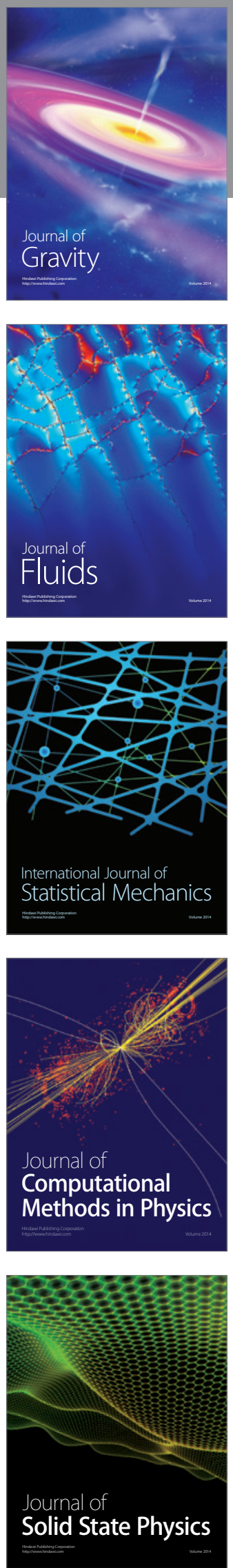

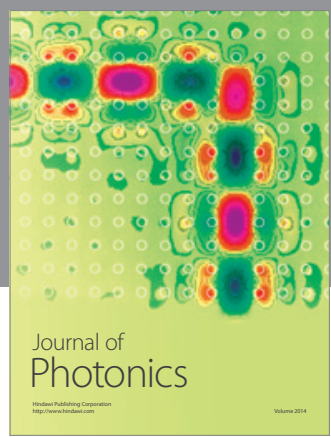

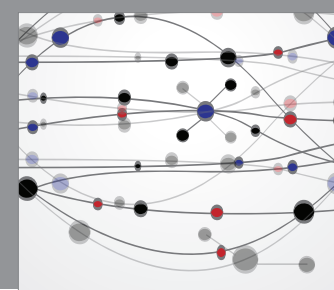

The Scientific World Journal

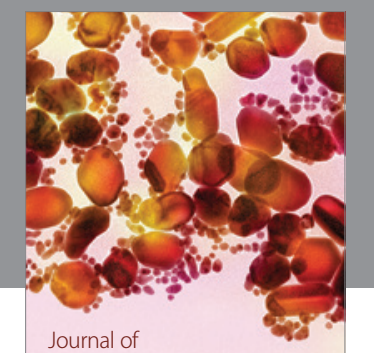

Soft Matter
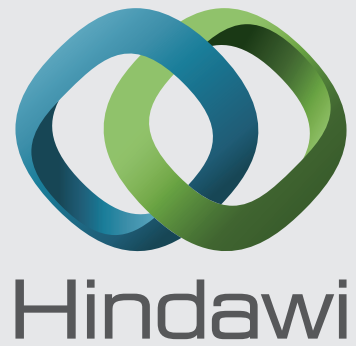

Submit your manuscripts at

http://www.hindawi.com
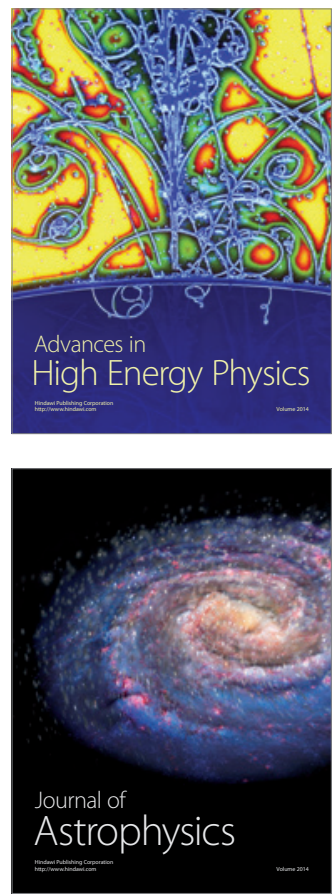
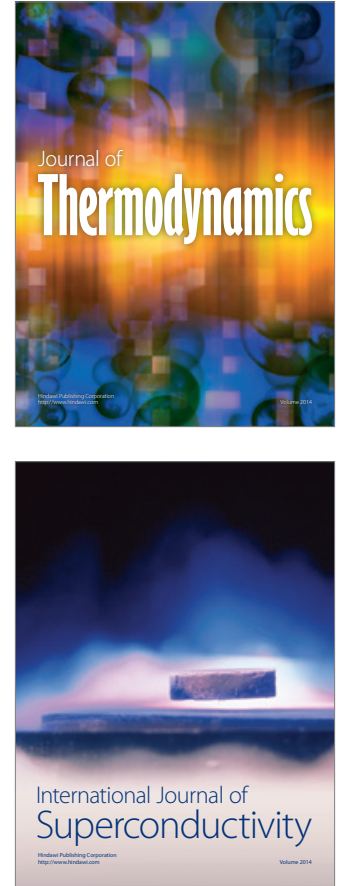
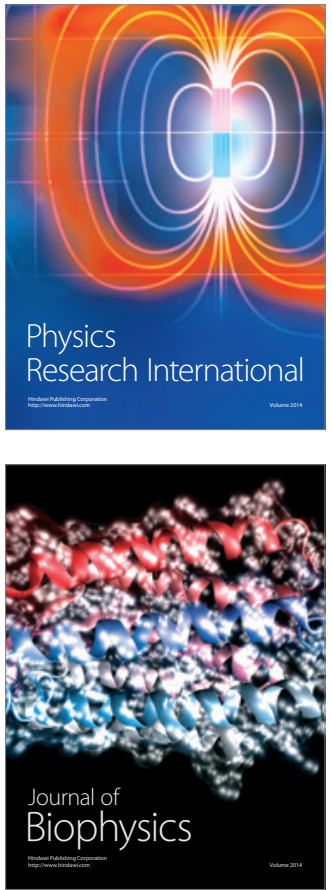
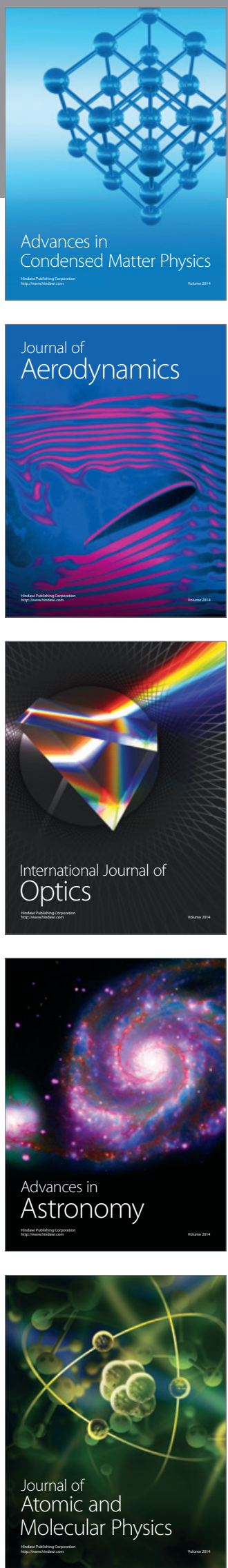